\title{
Effect of Implementing an Educational Module About Inhaler Use on Severity of Dyspnea and Adherence to Inhalation Therapy Among Patients with Chronic Obstructive Pulmonary Disease
}

\author{
Soheir M. Weheida ${ }^{1}$, Manal E. Fareed ${ }^{2}$, Samah E. Masry ${ }^{2}$ \\ ${ }^{1}$ Department of Medical Surgical Nursing, Faculty of Nursing, Alexandria University, Alexandria, Egypt \\ ${ }^{2}$ Department of Medical Surgical Nursing, Faculty of Nursing, Menoufia University, Shebin El-Kom, Egypt
}

Email address:

Manalfareed95@yahoo.com (M. E. Fareed), Drsamahmasry@gmail.com (S. E. Masry)

\section{To cite this article:}

Soheir M. Weheida, Manal E. Fareed, Samah E. Masry. Effect of Implementing an Educational Module About Inhaler Use on Severity of Dyspnea and Adherence to Inhalation Therapy Among Patients with Chronic Obstructive Pulmonary Disease. American Journal of Nursing Science. Vol. 6, No. 1, 2017, pp. 40-52. doi: 10.11648/j.ajns.20170601.16

Received: December 1, 2016; Accepted: December 15, 2016; Published: January 28, 2017

\begin{abstract}
One of the most important routes for medication administration to treat chronic obstructive pulmonary disease patients is the inhaled one. If this method is not proper, medications will not be effective. The aim of this study was to determine the effect of implementing an educational module about inhaler use on severity of dyspnea and adherence to inhalation therapy among patients with chronic obstructive pulmonary disease. A purposive sample of 140 patients with COPD was selected and divided randomly and alternatively into two equal groups, 70 in each. The study was conducted at Chest department and Medical outpatient clinics of Menoufia University and Shebin El-Kom Teaching Hospitals. Five tools were utilized for data collection: Structural interview questionnaire, Bristol COPD knowledge questionnaire, Pressurized metered dose inhaler performance observational checklist, Shortness of breath questionnaire and Morisky Medication adherence scale. Results: $62.9 \%$ of study group and $54.3 \%$ of control group complained of severe dyspnea pre education, while $44.3 \%$ of study group and $54.3 \%$ of control group still complained of severe dyspnea one month post education. The improvement of dyspnea among study group than control group was not significant. However medication adherence was significantly improved among study group compared to control group post education. Conclusion: educational module about inhaler use significantly led to improve medication adherence and decrease dyspnea severity however the difference in dyspnea severity among both groups is not significant. Recommendations: Patient's education about correct inhaler use should be ongoing process for all COPD patients and the correct use of inhaler should be observed throughout patient's life.
\end{abstract}

Keywords: Effect, Educational Modules, Inhaler Use, Dyspnea, Inhalation Therapy Adherence,

Obstructive Pulmonary Disease

\section{Introduction}

Chronic obstructive pulmonary disease (COPD) is a major health condition that characterized by irreversible progressive air flow limitation that leads to increase worldwide prevalence, morbidity and mortality [1]. In this condition, the airway becomes damaged making it increasingly difficult for air to pass in and out [2]. Moreover it affects the quality of life and economic status for those patients [3].

Most of the available information about COPD is from highly income countries. However, accurate epidemiological data are difficult and expensive to collect. In 2005 WHO estimated that, there are 210 million people diagnosed with COPD and three million patients were died of COPD. These deaths represent $5 \%$ of all deaths globally but approximately $90 \%$ of them occur in low income countries. In 2002, COPD was the fifth leading cause of death that will become the third cause worldwide in 2030. [4, 5]. According to statistics by country for COPD (2013), the extrapolation of undiagnosed prevalence rate of COPD in Egypt is 4,197,651 and the 
diagnosed prevalence rate is $3,777,886$ [6].

COPD is highly associated with over exposure to environmental factors especially tobacco smoke that is responsible about 80 to $90 \%$ of cases, occupational dust and air pollution [7]. Cough, sputum production and dyspnea on exertion as well as fatigue and sleep disturbances are the primary symptoms of COPD $[1,8]$. It also affects patients' physical functions, working and recreations activities, and emotional status as well as sexual relations [9].

Dyspnea is the subjective experience of unpleasant discomfort with breathing. It is a cardinal symptom of chronic obstructive pulmonary disease (COPD). The more progress, the more its severity and magnitudes that have negative impact on patient's abilities and quality of life to the extent that patients become isolated, often describing themselves as existing rather than living. Refractory dyspnea is a common and difficult symptom to treat in patients with advanced COPD. The most important question about the ideal management is whether various therapies are effective or not $[10,11]$.

The most important line of management strategies for COPD are risk reduction such as smoking cessation and proper vaccination for Influenza and Pneumococcus, symptoms relief and prevention of exacerbations [12]. These can be achieved by pharmacological management especially bronchodilator to relieve bronchospasm and reduce airway obstruction, corticosteroids to improve symptoms and oxygen therapy to prevent acute dyspnea [1]. Medications can be given by inhalation or orally, however the inhaled rout is the preferred one because by this route, patients may need low dose with faster action and fewer adverse effects. Moreover, medications go directly to the target region of respiratory tract $[13,14]$. For this reason the inhaled route is the route of choice for the treatment of most bronchial diseases especially COPD. The inhalation technique influences the drug deposition in the lung and enhances the effectiveness of the treatment for the patients with COPD although inhalation technique is often incorrect in many COPD patients [15].

There are many factors that affect the effectiveness of inhaled drugs such as patient's age, sex and education, duration of the disease, type of inhalers and correct inhalation technique [16]. However majority of COPD patients' incorrectly perform the inhalation technique. Many clinical studies reported that up to $90 \%$ of those patients show incorrect technique. This may lead to decrease disease control, increase the absenteeism from work or school, unnecessary increase in medication dosage, increase risk of side effects, non adherence to inhaled medication and exacerbations manifestations especially deterioration of dyspnea that requires oral corticosteroid treatment [17]. Many COPD patients are non adherent to the inhaled drugs so mortality rate is susceptible to increase more than twice among those patients compared to patients who adhere to the inhaled medications $[18,19]$.

Although COPD cannot be cured, optimal management provides symptom control, slows progression of the disease, and may improve the quality of life. Management of COPD becomes suboptimal due to poor adherence to evidencebased guidelines and under diagnosis or when patients fail to adhere to prescribed treatment regimens [20,21]. Adhering to inhaled medications is one of the most important factors for managing COPD in both clinical and ambulatory settings. In a recent study, it was shown that there was a significant decrease in the frequency of dyspnea, cough, sputum purulence or wheeze [18].

Moreover in a previous study, the instructions given repeatedly to COPD patients about inhalation technique contributed to adherence to therapeutic regimen that had a significant effect on health status [18]. Regular evaluation of inhalation technique is important to optimize treatment effectiveness and the inhalation technique can be significantly improved by brief instruction given by any trained health care personal on correct inhaler technique [17]. So this study aimed to determine the effect of implementing an educational module about inhaler use on severity of dyspnea and adherence to inhalation therapy among patients with chronic obstructive pulmonary disease.

\section{Subjects and Methods}

\subsection{Aim of the Study}

The aim of the study was to determine the effect of implementing an educational module about inhaler use on severity of dyspnea and adherence to inhalation therapy among patients with chronic obstructive pulmonary disease.

\subsection{Research Hypotheses}

The following research hypotheses were formulated to achieve the aim of the study:

a. Patients who follow educational module instructions about inhalation technique show a significant reduction in severity of dyspnea than patients who don't.

b. Patients who follow educational module instructions about inhalation technique exhibit medication adherence than patients who don't.

\subsection{Design}

A quasi experimental research design was utilized to achieve the aim of this study.

\subsection{Setting}

The current study was conducted at Chest department and Medical outpatient clinics of Menoufia University and Shebin El- Kom Teaching Hospitals.

\subsection{Subjects}

A purposive sample of 140 patients with chronic obstructive pulmonary disease was selected by using the following power analysis equation:- 


\subsubsection{Power Analysis}

The patients to be selected were determined by using the following equation: $n=(z 2 \times p \times q) / D 2$. Since the actual prevalence of COPD was $10 \%$, and a value of 0.025 was chosen as the acceptable limit of precision (D). Based on these assumptions, the sample size was estimated to be 140 patients. They were divided alternatively into two equal groups 70 patients in each.

Study group (1) received a detailed education and training about correct inhalation technique along with routine medical care such as administration of oxygen therapy and nebulizer.

Control group (2) was exposed to routine medical care only.

\subsubsection{Inclusion Criteria}

Subjects were considered eligible for the study if they had the following criteria:

- Adult conscious patients.

- Under inhalation therapy.

- Complained of dyspnea.

- Carry regular visits to medical outpatient clinics every one to three months.

- Free from any associated disorders.

\subsubsection{Sampling Technique}

The sample size was determined and calculated using EPI info program and it was estimated to be 138 patients at coefficient interval $99 \%$. The researchers increased the sample size to 140 patients.

\subsection{Tools}

For the aim of the study and to collect the necessary data, five tools were utilized by the researchers. These tools were as follow:

\subsubsection{Tool I: Structured Interviewing Questionnaire}

It was constructed by the researchers to collect data about biosociodemographic data. It covered the following two parts:

- Part one: Sociodemographic Data. It was comprised of seven items related to patients' age, sex, marital status, educational level, occupation, working hours and home status.

- Part two: Medical data. It was concerned with information related to medical data such as smoking status, patients' present complaints, use of oxygen, history of inhaler use, previous hospitalization, family history of lung diseases and environmental factors that may increase the intensity of symptoms.

\subsubsection{Tool II: Bristol COPD Knowledge Questionnaire (BCKO)}

It was developed by White et al., (2006) [22]. The questionnaire was translated into Arabic, back translated and linguistically validated then utilized by the researchers to assess patient's COPD related knowledge. It consisted of sixty five statement about COPD symptoms (such as ankle edema, fatigue, chest pain, dyspnea, sputum and rapid weight loss), manifestations of chest infection, benifits of exercises for COPD, importance of smoking cessation, vaccination and medications especially inhaled bronchodilators, antibiotics and chorticosteroides.

Scoring system: Each item was given a score of one if the answer is correct and zero if the answer is wrong or don't know, then all scores were summed. The possible score ranged from zero to sixty five and the patients were categorized into two groups based on their scores: A BCKO score of 28 or more was considered high knowledge, while a score of less than 28 was considered low knowledge score.

Reliabilty Lee et al., (2014) [23] tested the reliability of the english version of the questionnaire, it was demonstrated to be 0.82 with strong test re-test agreement. while the researchers used a test re-test method to test reliabilty of the questionnaire after translation, it was 0.84 .

\subsubsection{Tool III: Pressurized Metered Dose Inhaler Performance Observational Chicklist}

It was developed by the researchers according to the guidelines of the inhaler manufacture to assess patient's performance of pressurized metered dose inhaler such as removing the cap, holding inhaler uprightly, breathing out gently, putting mouthpiece between teeth and breathing in slowly through mouth, etc. The number of chicklist's steps were eleven. The patient was given one degree for each step that was performed accurately or zero for inaccurate technique or skipped step then all degrees were summed. Subjects were considered to have good performance if he had seven degrees or more. The more the degree, the higher the performance.

\subsubsection{Tool VI: Shortness of Breath Questionnaire}

It was developed by Eakin et al., (1998) [24] and used by the researchers to rate patient's breathlessness and assess which physical activity that may percipitate breathlessness. It consisted of 24 listed phsical activities to be assessed if it perciptitate dyspnea or not such as shortness of breathing at rest, at walking on a level at own pace, walking upstairs, while eating, dressing, doing dishes, and shopping.

Scoring system: the questionnaire is a six point likert scale rated from zero to five in which:

Zero is not at all breathlessness

1 . is very mild breathlessness

2. is mild breathlessness

3. is avarage breathlessness

4. is severe breathlessness

5. is maximum breathlessness or unable to do the activity because of breathlessness. The total scores were summed that ranged from zero to one hundered twenty with higher score indicated inability to do any activity because of breathlessness.

Reliability: Tabberer et al., (2015) [25] tested the reliability of the questionnaire. They found that this questionnaire had high internal consistency (Cronbach's alpha $=0.936$ ) with high test re-test reliability (Pearson's correlation coefficient $=0.86$ ). 


\subsubsection{Tool V: Morisky Medication Adherence Scale (MMAS)}

It was developed by Morisky et al., (1986) [26] and used by the researchers to assess patient's adherence to the prescribed inhaled medications. It consisted of eight questions about adherence to the prescribed medications such as did patient sometimes miss the medication, did he/she stopped taking the medication for reason other than forgetting or have the patient stopped taking medication without telling the doctor.

Scoring system: each item was given a score of zero if patient adhere to the prescribed medications and one for nonadherence, then all scores were summed given a score of:

Zero means high adherence

1-2 means medium adherence

3-8 means low adherence

Reliability: Moharamazad et al., (2015) [27] told that a test re-test reliability showed good reproducibility $(\mathrm{r}=0.94)$

\subsection{Methods}

(1) Data was collected from the beginning of March 2014 to the end of August 2015.

(2) An official approval was obtained from hospitals' director and the head nurses of the Chest department and Medical outpatient clinics after an explanation of the aim of the study.

\subsubsection{Tools Development}

- The first and third tools were developed by the researchers after extensive review of the relevant literature. While the second tool was developed by White et al., (2006) [22] and translated into Arabic by the researchers, fourth one developed by Eakin et al., (1998) [24] and the fifth tool developed by Morisky et al., (1986) [26].

- First and third tools were tested by a panel of five experts in the field of Nursing and Medicine to determine its content validity, relevance and completeness. While the second tool was translated into Arabic, back translated and linguistically validated by the same panel of experts.

- The reliability of the first and third tools were tested by using a test re-test method and the ${ }^{4}$ Pearson correlation coefficient. It was 0.91 for tool I and 0.94 for the third tool. Also the second tool was tested for reliability by the researchers after translation into Arabic by using a test re test method. It was 0.84 .

(3) A formal consent to participate in this study was obtained from all participants after explaining the aim of the study and they were assured that all collected data would be absolutely confidential and only will be used for the study' aim. The researchers emphasized that participation in the study is entirely voluntary and anonymity of the patients were assured through coding data. Subjects were also informed that refusal to participate in the study would not affect their care.

\subsubsection{Pilot Study}

A pilot study was conducted prior to data collection on 14 patients $(10 \%)$ to test all tools for clarity, objectivity, relevance, feasibility and the applicability of the tools. Also it was conducted to identify any problem associated with administering the tools and measure the time needed for data collection then the necessary modifications were carried out accordingly. Data included in pilot study was excluded from the current study

\subsubsection{Data Collection}

- The patients who fulfilled the inclusion criteria were selected and divided randomly and alternatively into two equal groups

- Study group (1) received a detailed education and training about correct inhalation technique along with routine medical care such as administration of oxygen therapy and nebulizer.

- Control group (2) was exposed to routine medical care only.

- The study was conducted in four consecutive phase. These phases were:-

\subsubsection{Assessment Phase}

- The first interview was carried out by the researchers for each participant of both groups for collecting baseline data about sociodemographic and medical data, COPD related knowledge, severity of dyspnea, and medication adherence level. The interview carried out often in the patient's room with hospitalized patients or in the waiting area of outpatient clinics if he/she wasn't hospitalized. It took about 25 to 30 minute using tool I, tool II, tool VI and tool V.

- Then the researchers utilized the third tool (observational checklist) to assess each participant of both groups for their performance of inhaler use.

\subsubsection{Planning Phase}

Based on assessment phase and extensive literature review $[2,6]$ educational needs were identified for each individual patient of study group (group I) then a colored written pocket sized booklet was prepared putting into consideration the outcome criteria, it includes the following information:-

- COPD related knowledge such as definition, causes, pathophysiology, manifestations and methods of prevention.

- Dangers of infection and smoking for COPD patient.

- Management strategies and its importance such as exercises, vaccination, inhaled medications and its effect especially inhaled bronchodilators, antibiotics and corticosteroids.

- Procedure of correct technique of pressurized metered dose inhaler according to the inhaler manufacture that describes all the necessary steps to perform the correct technique including images to illustrate the steps beginning from removing cap, holding the inhaler uprightly and shaking it well, breathing out gently, putting the mouthpiece between teeth without biting, till 
replacing the cap again.

\subsubsection{Implementation Phase}

- The researchers conducted three teaching sessions for each participant of group I. Each session took about 30 minutes either in Chest department or in the waiting area of Medical outpatient clinics. Moreover the designed booklet was distributed by the researchers for each participant in group I before the first session.

- Participants in Chest department were interviewed in small group (3 patients), while other patients in outpatient clinics were interviewed individually. Each session was conducted using lectures, group discussion, demonstration, re-demonstration

- During the first session: information about the disease, definition, causes, manifestations and methods of prevention.

- The second session was about impact of infection and smoking on COPD patients and the treatment strategies.

- During the third session the researchers demonstrated all the correct route of pressurized metered dose inhaler. Then the researchers carried revision and reinforcement according to participant's needs. Also the researchers corrected the wrong performance of inhaler use and answered questions.

\subsubsection{Evaluation Phase}

- Evaluation of all subjects of both groups was done twice during the study period. The first time post two weeks from last session and the other after one month using all tools.

- A comparison between both groups was carried out to determine the effect of education about inhaler use on severity of dyspnea and adherence to inhalation therapy among patients with chronic obstructive pulmonary disease.

\subsubsection{Statistical Analysis}

The collected data were organized, tabulated and statistically analyzed using SPSS software (Statistical Package for the Social Sciences, version 16, SPSS Inc. Chicago, IL, USA). For quantitative data, the range, mean and standard deviation were calculated. For qualitative data, comparison between two groups and more was done using Chi-square test $\left(\chi^{2}\right)$. For comparison between means of two groups of parametric data of independent samples, student t-test was used. For comparison between more than two means of parametric data, F value of ANOVA test was calculated. Correlation between variables was evaluated using Pearson's correlation coefficient (r). Significance was adopted at $\mathrm{p}<0.05$ for interpretation of results of tests of significance [28].

\section{Results}

Table 1 illustrated that the mean age for study group was $57.77 \pm 12.43$ years and for control group was $56.77 \pm 11.37$ years. More than three fourths of both study and control groups were married $(78.6 \%$ and $87.1 \%$ respectively). About one third of them had secondary education $(37.1 \%$ for study group and $30.0 \%$ for control group). Regarding working hours, about half of both study and control groups $(59.3 \%$ and $48.4 \%$ respectively) worked eight hours per day. In relation to the home condition, it was show that the majority of both groups had sun in their houses $(85.7 \%$ and $88.6 \%$ respectively) and proper room ventilation $(84.3 \%$ and $88.6 \%$ respectively). Also about two thirds of both groups had sewage $(68.6 \%$ and $62.9 \%$ respectively. Lastly about one third of study group (31.4\%) and more than half of control group $(51.4 \%)$ gave up smoking.

Table 2 revealed that about two thirds of both study and control groups (62.9\% and $71.4 \%$ respectively) visited output clinic once per week. More than one third of both groups $(42.9 \%$ and $37.1 \%)$ complained of productive cough, wheezing, and dyspnea. All subjects of both groups (100\%) used oxygen during attack. Regarding duration of inhaler use, the majority of both groups $(80.0 \%$ and $82.9 \%$ respectively) used the inhaler from two or more years. All of them $(100 \%)$ received training about inhaler use but none of them $(0.0 \%)$ followed up this training. As regard family history of lung diseases, the majority of both groups $(81.4 \%$ and $87.1 \%$ respectively) didn't have positive family history. Smoke was the most aggravating factors for the disease manifestations about one third of both groups $(32.9 \%$ and $41.4 \%$ respectively).

Table 3 showed that about one quarter of both study and control groups $(24.3 \%$ and $25.7 \%$ respectively) had low knowledge score at pre intervention. These scores were improved after two weeks and one month post intervention. $100 \%$ of study group and $74.3 \%$ of the control group had a high knowledge score two weeks and one month post intervention. Statistically significant differences were existed between both groups two weeks and one month post intervention.

Figure 1 revealed that mean total performance score of inhaler use for study group was significantly improved throughout the study period from $6.06 \pm 0.63$ pre interventions to $9.71 \pm 1.10$ two weeks and one month post intervention. While the mean total performance score for control group remained stable all over the study period at $6.13 \pm 0.74$. Statistical significant differences existed between both groups two weeks and one month post intervention at $(\mathrm{p}=0.0001)$.

Table 4 demonstrated that about two thirds of study group I $(62.9 \%)$ and more than half of control group II $(54.3 \%)$ complained of severe dyspnea, while one month after education only $44.3 \%$ of study group still complained of severe dyspnea compared to $54.3 \%$ of control group with insignificant differences existed between both groups.

Table 5 showed that only $4.3 \%$ of study group adhere moderately to medication pre intervention that was significantly improved to $47.1 \%$ two weeks and one month post intervention. But control group remained stable all over the study period with $10 \%$ of them had moderate adherence to medication. There were statistical significant differences between both groups two weeks and one month post intervention. 
Table 6 revealed that there was statistical significant difference between dyspnea severity scores in relation to disease duration among study group.

Table 7 showed that no statistical significant differences were existed between medication adherence levels in relation to selected sociodemographic characteristics among study and control groups.

Table 8 shows that a negative correlation was found among dyspnea severity score and knowledge score for study group post intervention.

Table 1. Distribution of Sociodemographic data of both studied subjects $(n=140)$.

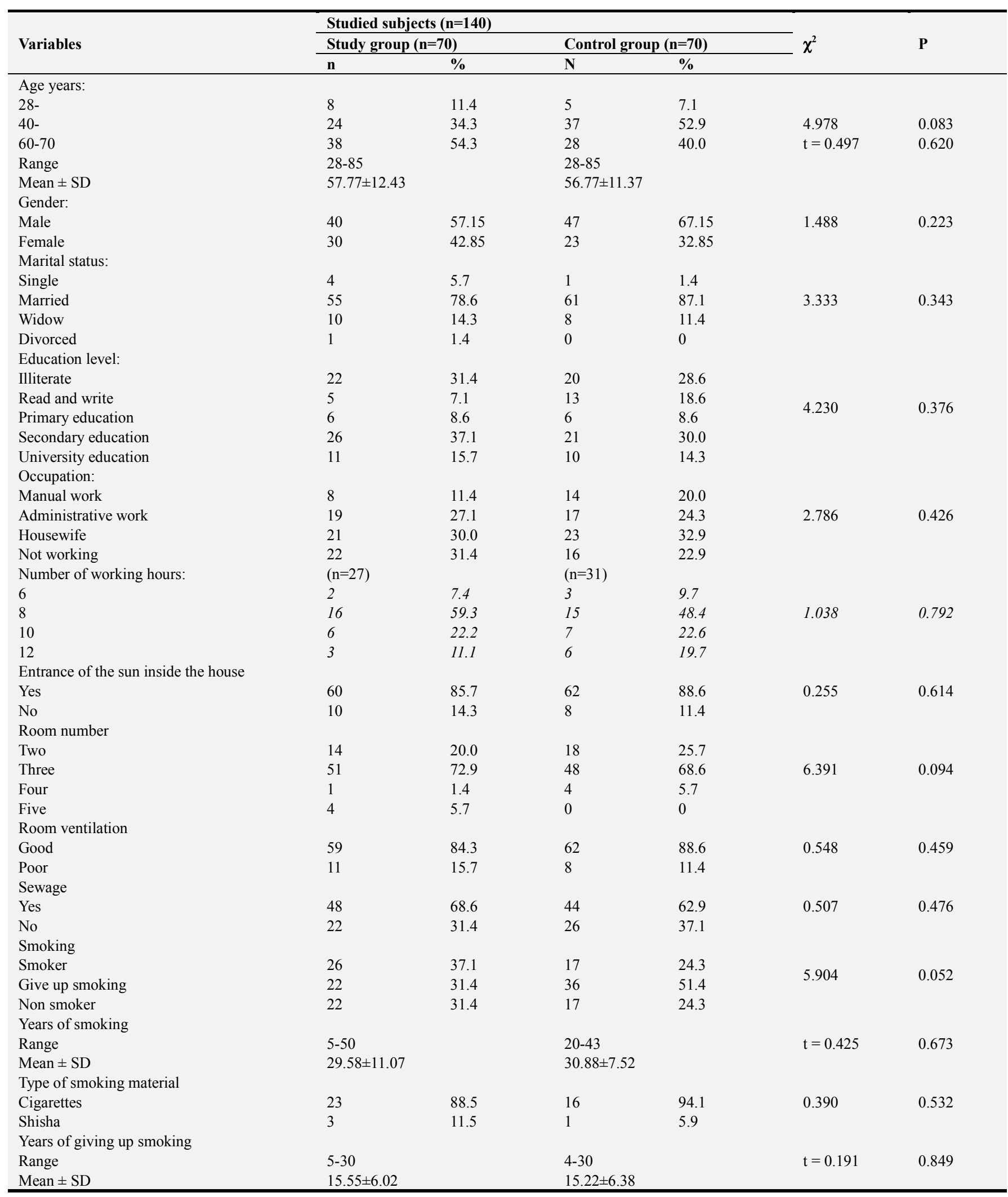


Table 2. Distribution of both studied subjects regarding medical data $(n=140)$.

\begin{tabular}{|c|c|c|c|c|c|c|}
\hline \multirow{3}{*}{ Variables } & \multicolumn{4}{|c|}{ The studied subjects $(n=140)$} & \multirow{3}{*}{$\chi^{2}$} & \multirow{3}{*}{$\mathbf{P}$} \\
\hline & \multicolumn{2}{|c|}{ Study group $(n=70)$} & \multicolumn{2}{|c|}{ Control group $(n=70)$} & & \\
\hline & $\mathbf{n}$ & $\%$ & $\mathbf{n}$ & $\%$ & & \\
\hline \multicolumn{7}{|c|}{ Number of outpatient follow up/week } \\
\hline One & 44 & 62.9 & 50 & 71.4 & \multirow[t]{2}{*}{1.166} & \multirow[t]{2}{*}{0.280} \\
\hline Two & 26 & 37.1 & 20 & 28.6 & & \\
\hline \multicolumn{7}{|l|}{ Current patient's complain } \\
\hline Productive cough and dyspnea & 24 & 34.3 & 22 & 31.4 & \multirow{4}{*}{0.856} & \multirow{4}{*}{0.652} \\
\hline Chest wheezing and dyspnea & 8 & 11.4 & 12 & 17.1 & & \\
\hline Dyspnea alone & 8 & 11.4 & 10 & 14.3 & & \\
\hline Other (all of the above) & 30 & 42.9 & 26 & 37.1 & & \\
\hline \multicolumn{7}{|l|}{ Disease duration (years) } \\
\hline 2- & 5 & 7.1 & 7 & 10.0 & \multirow{5}{*}{$\begin{array}{l}0.511 \\
\mathrm{t}=0.185\end{array}$} & \multirow{5}{*}{$\begin{array}{l}0.775 \\
0.853\end{array}$} \\
\hline 5- & 29 & 41.4 & 26 & 37.1 & & \\
\hline $10-20$ & 36 & 51.4 & 37 & 52.9 & & \\
\hline Range & $2-2$ & & $4-2$ & & & \\
\hline Mean $\pm \mathrm{SD}$ & 11.1 & & 11.2 & & & \\
\hline \multicolumn{7}{|l|}{ Duration of inhaler use (years) } \\
\hline Less than two years & 14 & 20.0 & 12 & 17.1 & \multirow[t]{2}{*}{0.189} & \multirow[t]{2}{*}{0.664} \\
\hline Two years or more & 56 & 80.0 & 58 & 82.9 & & \\
\hline \multicolumn{7}{|l|}{ Frequency of inhaler use/day } \\
\hline With Dyspnea attack & 22 & 31.4 & 17 & 24.3 & \multirow{3}{*}{1.867} & \multirow{3}{*}{0.172} \\
\hline $1-2$ times/day & 26 & 37.2 & 17 & 24.3 & & \\
\hline More than 2 times/day & 22 & 31.4 & 36 & 51.4 & & \\
\hline \multicolumn{7}{|c|}{ Number of admission to emergency unit } \\
\hline None & 3 & 4.3 & 6 & 8.6 & \multirow{4}{*}{3.088} & \multirow{4}{*}{0.378} \\
\hline $1-2$ & 36 & 51.4 & 33 & 47.1 & & \\
\hline 3- 4 & 27 & 38.6 & 30 & 42.9 & & \\
\hline 5- 6 & 4 & 5.7 & 1 & 1.4 & & \\
\hline \multicolumn{7}{|l|}{ Causes of admission } \\
\hline Shortness of breath and cough & 40 & 59.7 & 32 & 50.0 & 1.245 & 0.265 \\
\hline Dyspnea, wheezing, and fever & 27 & 40.3 & 32 & 50.0 & & \\
\hline Family history of lung diseases & & & & & & \\
\hline Yes & 13 & 18.6 & 9 & 12.9 & 0.863 & 0.353 \\
\hline No & 57 & 81.4 & 61 & 87.1 & & \\
\hline Aggravating factors for disease & & & & & & \\
\hline Dust & 22 & 31.4 & 17 & 24.3 & & \\
\hline Smoke & 23 & 32.9 & 29 & 41.4 & 2420 & 0656 \\
\hline Cold weather & 7 & 10.0 & 6 & 8.6 & 2.439 & 0.656 \\
\hline Hot weather & 1 & 1.4 & 0 & 0 & & \\
\hline Fatigue and increase activities & 17 & 24.3 & 18 & 25.7 & & \\
\hline
\end{tabular}

NB.

- All subjects of both groups $(100 \%)$ used $\mathrm{O}_{2}$ therapy during the attack

- All subjects of both groups (100\%) mentioned that were received previous training about inhaler use but didn't follow up this training.

Table 3. Levels of total Bristol COPD knowledge among both studied subjects pre, two weeks and one month post education (n=140).

\begin{tabular}{|c|c|c|c|c|c|c|}
\hline \multirow{3}{*}{ Total Bristol COPD knowledge } & \multicolumn{4}{|c|}{ The studied COPD patients $(n=140)$} & \multirow{3}{*}{$\chi^{2}$} & \multirow{3}{*}{$\mathbf{P}$} \\
\hline & \multicolumn{2}{|c|}{ Study group $(n=70)$} & \multicolumn{2}{|c|}{ Control group $(n=70)$} & & \\
\hline & $\mathbf{n}$ & $\%$ & $\mathbf{N}$ & $\%$ & & \\
\hline \multicolumn{7}{|l|}{ Pre-intervention } \\
\hline Low knowledge score & 17 & 24.3 & 18 & 25.7 & 0.03 & 0.845 \\
\hline High knowledge score & 53 & 75.7 & 52 & 74.3 & & \\
\hline \multicolumn{7}{|l|}{ Two weeks post intervention } \\
\hline Low knowledge score & 0 & 0 & 18 & 25.7 & 20.65 & $0.0001 *$ \\
\hline High knowledge score & 70 & 100 & 52 & 74.3 & & \\
\hline \multicolumn{7}{|l|}{ One month post-intervention } \\
\hline Low knowledge score & 0 & 0 & 18 & 25.7 & 20.65 & $0.0001^{*}$ \\
\hline High knowledge score & 70 & 100 & 52 & 74.3 & & \\
\hline
\end{tabular}


Table 4. Distribution of both studied subjects regarding dyspnea severity among studied subjects pre, two weeks and one month post education.

\begin{tabular}{|c|c|c|c|c|c|c|}
\hline \multirow{3}{*}{ Dyspnea } & \multicolumn{4}{|c|}{ The studied COPD patients $(n=140)$} & \multirow{3}{*}{$\chi^{2}$} & \multirow{3}{*}{$\mathbf{P}$} \\
\hline & \multicolumn{2}{|c|}{ Study group $(n=70)$} & \multicolumn{2}{|c|}{ Control group $(\mathrm{n}=70)$} & & \\
\hline & $\mathbf{n}$ & $\%$ & $\mathbf{N}$ & $\%$ & & \\
\hline \multicolumn{7}{|c|}{ Pre education } \\
\hline Mild & 26 & 37.1 & 32 & 45.7 & 1.060 & 0.303 \\
\hline Severe & 44 & 62.9 & 38 & 54.3 & & \\
\hline \multicolumn{7}{|c|}{ Two weeks post education } \\
\hline Mild & 26 & 37.1 & 30 & 42.9 & 0.476 & 0.490 \\
\hline Severe & 44 & 62.9 & 40 & 57.1 & & \\
\hline \multicolumn{7}{|c|}{ One month post education } \\
\hline Mild & 39 & 55.7 & 32 & 45.7 & 1.400 & 0.237 \\
\hline Severe & 31 & 44.3 & 38 & 54.3 & & \\
\hline
\end{tabular}

Table 5. Levels of medication adherence among both studied subjects pre, two weeks and one month post-education ( $n=140)$.

\begin{tabular}{|c|c|c|c|c|c|c|}
\hline \multirow{3}{*}{ Morisky medication adherence } & \multicolumn{4}{|c|}{ The studied COPD patients $(n=140)$} & \multirow{3}{*}{$\chi^{2}$} & \multirow{3}{*}{$\mathbf{P}$} \\
\hline & \multicolumn{2}{|c|}{ Study group $(n=70)$} & \multicolumn{2}{|c|}{ Control group $(n=70)$} & & \\
\hline & $\mathbf{n}$ & $\%$ & $\mathbf{N}$ & $\%$ & & \\
\hline \multicolumn{7}{|l|}{ Pre education } \\
\hline High adherence & 3 & 4.3 & 7 & 10.0 & 1.723 & 0.189 \\
\hline Low adherence & 67 & 95.7 & 63 & 90.0 & & \\
\hline \multicolumn{7}{|l|}{ Two weeks post education } \\
\hline Low adherence & 37 & 52.9 & 63 & 90.0 & & \\
\hline \multicolumn{7}{|l|}{ One month post education } \\
\hline High adherence & 33 & 47.1 & 7 & 10 & 23.660 & $0.0001 *$ \\
\hline Low adherence & 37 & 52.9 & 63 & 90.0 & & \\
\hline
\end{tabular}

Table 6. Mean scores of dyspnea severity pre education among the studied subjects in relation to sociodemographic data and duration of disease ( $n=140)$.

\begin{tabular}{|c|c|c|c|c|}
\hline \multirow{3}{*}{ Items } & \multicolumn{4}{|c|}{ The studied COPD patients $(n=140)$} \\
\hline & \multicolumn{2}{|l|}{ Study group $(n=70)$} & \multicolumn{2}{|c|}{ Control group $(n=70)$} \\
\hline & Mean \pm SD & t-test or $F$ value $P$ & Mean \pm SD & t-test or $F$ value $P$ \\
\hline \multicolumn{5}{|l|}{ Age years } \\
\hline $28-$ & $20.25 \pm 4.27$ & & $19.60 \pm 2.70$ & \\
\hline $40-$ & $21.58 \pm 3.37$ & 0.784 & $21.14 \pm 3.56$ & 0.591 \\
\hline $60-70$ & $21.84 \pm 2.97$ & 0.461 & $20.32 \pm 4.23$ & 0.557 \\
\hline \multicolumn{5}{|l|}{ Occupation } \\
\hline manual work & $19.75 \pm 3.99$ & & $22.07 \pm 3.95$ & \\
\hline Administrative work & $20.89 \pm 3.83$ & & $19.18 \pm 3.17$ & \\
\hline Housewife & $22.48 \pm 2.58$ & 1.807 & $21.00 \pm 3.93$ & 1.628 \\
\hline Not working & $21.95 \pm 2.84$ & 0.154 & $20.69 \pm 3.77$ & 0.191 \\
\hline \multicolumn{5}{|l|}{ House condition } \\
\hline Entrance of the sun inside the house & $21.47 \pm 3.32$ & 0.656 & $20.81 \pm 3.71$ & 0.654 \\
\hline No entrance of the sun inside the house & $22.20 \pm 2.94$ & 0514 & $19.88 \pm 4.42$ & 0.516 \\
\hline \multicolumn{5}{|l|}{ Room ventilation } \\
\hline Good & $21.53 \pm 3.17$ & 0.272 & $20.56 \pm 3.80$ & 0.833 \\
\hline Poor & $21.82 \pm 0.87$ & 0.787 & $21.75 \pm 3.61$ & 0.407 \\
\hline \multicolumn{5}{|l|}{ Sewage } \\
\hline Yes & $21.44 \pm 3.60$ & 0.505 & $20.75 \pm 4.13$ & 0.143 \\
\hline No & $21.86 \pm 2.40$ & 0.615 & $20.62 \pm 3.18$ & 0.887 \\
\hline \multicolumn{5}{|l|}{ Smoking } \\
\hline Smoker & $21.23 \pm 3.90$ & 0.738 & $20.00 \pm 3.76$ & 0.498 \\
\hline Give up smoking & $21.27 \pm 3.03$ & 0.482 & $20.75 \pm 3.86$ & 0.610 \\
\hline Non smoker & $22.27 \pm 2.62$ & & $21.29 \pm 3.74$ & \\
\hline \multicolumn{5}{|l|}{ Disease duration (years) } \\
\hline $2-5$ & $18.40 \pm 3.71$ & 3.852 & $20.00 \pm 2.71$ & $0.415^{*}$ \\
\hline$>5-10$ & $21.45 \pm 3.32$ & $0.045^{*}$ & $20.35 \pm 3.36$ & $0.662 * *$ \\
\hline$>10-20$ & $22.11 \pm 2.96$ & & $21.08 \pm 4.23$ & \\
\hline
\end{tabular}


Table 7. Mean scores of medication adherence pre education among studied subjects in relation to sociodemographic data and duration of disease ( $n=140$ ).

\begin{tabular}{|c|c|c|c|c|}
\hline \multirow{3}{*}{ Items } & \multicolumn{4}{|c|}{ The studied COPD patients $(n=140)$} \\
\hline & \multicolumn{2}{|c|}{ Study group $(n=70)$} & \multicolumn{2}{|c|}{ Control group $(n=70)$} \\
\hline & Mean \pm SD & t-test or $F$ value $P$ & Mean \pm SD & t-test or $F$ value $P$ \\
\hline \multicolumn{5}{|l|}{ Age years: } \\
\hline 28- & $5.38 \pm 1.06$ & 0.238 & $2.88 \pm 0.99$ & 1.096 \\
\hline 40- & $5.33 \pm 1.63$ & 0.789 & $2.75 \pm 0.94$ & 0.340 \\
\hline $60-70$ & $5.55 \pm 1.43$ & & $2.50 \pm 0.69$ & \\
\hline \multicolumn{5}{|l|}{ Education level: } \\
\hline Illiterate & $5.59 \pm 1.40$ & 1.071 & $2.55 \pm 0.80$ & 0.184 \\
\hline Read and write & $6.40 \pm 1.34$ & 0.378 & $2.60 \pm 0.55$ & 0.946 \\
\hline Primary education & $4.67 \pm 2.07$ & & $2.83 \pm 0.75$ & \\
\hline Secondary education & $5.42 \pm 1.47$ & & $2.62 \pm 0.90$ & \\
\hline University education & $5.27 \pm 1.10$ & & $2.73 \pm 0.90$ & \\
\hline \multicolumn{5}{|c|}{ Disease duration (years): } \\
\hline $2-5$ & $5.80 \pm 1.09$ & 0.512 & $2.80 \pm 1.09$ & 1.923 \\
\hline$>5-10$ & $5.52 \pm 1.35$ & 0.238 & $2.83 \pm 0.66$ & 0.154 \\
\hline$>10-20$ & $5.36 \pm 1.59$ & & $2.44 \pm 0.88$ & \\
\hline
\end{tabular}

Table 8. Correlation between scores of knowledge, performance, dyspnea severity and medication adherence among the studied subjects pre education $(n=140)$.

\begin{tabular}{|c|c|c|c|c|c|c|}
\hline \multirow{5}{*}{ Items } & \multicolumn{6}{|c|}{ The studied COPD patients $(n=140)$} \\
\hline & \multicolumn{3}{|c|}{ Study group $(n=70)$} & \multicolumn{3}{|c|}{ Control group $(n=70)$} \\
\hline & $\begin{array}{l}\text { Bristol COPD } \\
\text { knowledge } \\
\text { scores }\end{array}$ & $\begin{array}{l}\text { Performance } \\
\text { of inhaler use } \\
\text { scores }\end{array}$ & $\begin{array}{l}\text { Dyspnea } \\
\text { severity } \\
\text { scores }\end{array}$ & $\begin{array}{l}\text { Bristol COPD } \\
\text { knowledge } \\
\text { scores }\end{array}$ & $\begin{array}{l}\text { Performance of } \\
\text { inhaler use scores }\end{array}$ & $\begin{array}{l}\text { Dyspnea } \\
\text { severity scores }\end{array}$ \\
\hline & $\mathbf{r}$ & $\mathbf{r}$ & $\mathbf{r}$ & $\mathbf{r}$ & $\mathbf{r}$ & $\mathbf{R}$ \\
\hline & $\mathbf{P}$ & $\mathbf{P}$ & $\mathbf{P}$ & $\mathbf{P}$ & $\mathbf{P}$ & $\mathbf{P}$ \\
\hline Bristol COPD knowledge scores & - & - & - & - & - & - \\
\hline Dyspnea severity scores & $\begin{array}{l}-0.012 \\
0.921\end{array}$ & $\begin{array}{l}0.098 \\
0.418\end{array}$ & - & $\begin{array}{l}0.045 \\
0.905\end{array}$ & $\begin{array}{l}0.055 \\
0.649\end{array}$ & - \\
\hline & 0.169 & 0.009 & 0.108 & 0.065 & 0.067 & 0.121 \\
\hline Morisky medication adherence scores & 0.163 & 0.940 & 0.375 & 0.590 & 0.583 & 0.319 \\
\hline
\end{tabular}

$\mathrm{r}=$ Correlation Coefficient

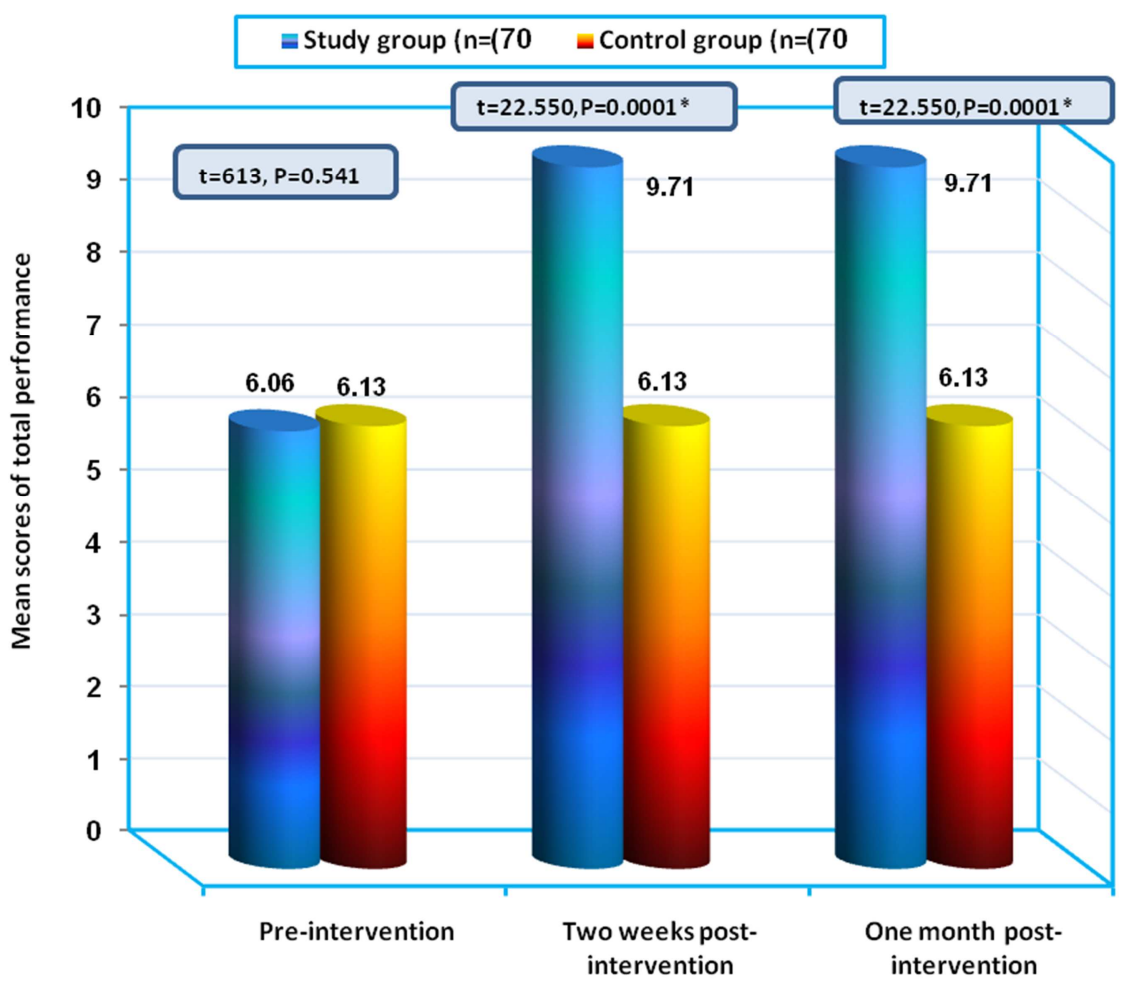

Figure 1. Mean scores of total performance of inhaler use among studied subjects pre, two weeks and one month post education (n=140). 


\section{Discussion}

The inhaled medications are the corner stone of therapy among patients with obstructive lung diseases and the inhaler is the only device for administrating the medication effectively which allows the drugs to be highly deposited in the lungs and it also minimizes the systemic adverse drug reaction [29].

Education of patients and their families has a major concern in recent years. This has been motivated by patient's needs for knowing more about their diseases so any health care personal should consider the self management as an important aspect for patient's recovery [22]. New evidence reported that control of COPD symptoms can be improved by brief verbal instructions and demonstration of correct inhaler technique [17].

Biosociodemographic characteristics of studied subjects: The results of present study found that the mean age of study group was $57.77 \pm 12.43$ years and $56.77 \pm 11.37$ years for control group. This finding is in line with Salah et al., (2013) who stated that the mean age of their sample was $55 \pm 5.7$ years [30] and Tel et al., (2012) who found that the mean age of their patients was $66.03 \pm 11.33$ years [31]. Also Wisniewski et al., (2014) revealed that the mean age of their studied patients was $63.7 \pm 7.1$ years [32]. This may be related to the incidence of COPD is growing among older age.

Concerning sex, the current study reported that more than half of studied subjects of both groups were male. These percentages are less than the percentage of Salah et al., (2013) and Akinci and Yildrin (2013) who stated that most of their sample was male $[30,33]$. This may be due to the lower sample size of the current study in relation to their sample size. The majority of both groups of the current study were married. This is consistent with the mean age of them.

Regarding home condition, the present study revealed that the home of majority of both groups was in good condition (sun entered the home, the houses were not crowded, good ventilated, and had sewage), so home condition is not a factor for the disease's symptoms.

National Heart, Lung and Blood Institute (2013) stated that patients with a history of smoking are more vulnerable to COPD [34]. This is in line of our study which showed that more than two thirds of studied subjects had history of smoking. They were either current or former smokers. While the current smokers represented about one third of both study and control groups for the present study. This is in line with Wisniewski et al., (2014) and Fernandz et al. (2014) [32, 35].

The mean years of disease duration for subjects of the current study was $11.11 \pm 3.52$ years for study group and $11.23 \pm 3.78$ years for control group. This result is near the results of Akinci and Yildrin (2013) [33] who found that the mean years of disease duration for their sample was $9.1 \pm 8.5$ years.

The results of the present study showed that all subjects of both groups received pervious training about inhaler use but all of them didn't follow this training. These findings are in accordance with the findings of Fadaei et al., (2016) who found that approximately all of their subjects were trained in this regard but didn't follow these training [36]. These findings were explained by Restrepo et al., (2008) who reported that retention of instructions about appropriate use of inhaler is lost over time [37].

It was stated that patient's education is one of the most important roles for a nurse in any health care setting and the nurse provides the patients with the needed information for self care to ensure continuity of care [38]. In the current study, it was noticed that the total knowledge score of study group was improved than control group post education by two weeks and one month. The result is in line with Khdour et al., (2009) and Jarab et al., (2012) who reported that the study group showed improvement of COPD knowledge when compared with control group [39, 40]. Also El-Sayed et al., (2012) found a statistical improvement of total knowledge score among study group than control group post education [41].

\section{Performance of inhaler use}

Correct inhaler technique is very important, however previous studies reported that incorrect inhaler technique is common among patients with asthma or COPD [16, 42]. These studies coincide with the results of our study which stated that pre education, the mean total performance of inhaler use was low for both study and control groups. While after education by two weeks and one month, there was a significant improvement in mean total performance score of inhaler use among study group than control group. These results are supported by National asthma council (2008) which stated that large body of evidence from randomized trials have shown that patient's inhaler technique can be improved by education [17]. Also Fadaei et al., (2014) revealed that using inhaler correctly requires the patients to be informed about proper use instructions [36].

Severity of dyspnea

One of the most severe symptoms of chronic obstructive pulmonary disease is dyspnea and its severity increases as the disease progresses [43]. The inhaled bronchodilators are considered a corner stone for treating dyspnea but incorrect inhaler use can reduce medication effectiveness that can lead to symptoms exacerbation especially dyspnea [44, 45]. This is in agreement with the results of the current study which showed that more than half of both groups had severe dyspnea pre correct inhaler's education. Improvement in dyspnea severity was observed among study group after one month than control group; however this improvement is not statistically significant. This result didn't support hypothesis number one. This may be due to the short follow up period and the improvement of dyspnea may require long follow up period however the better result observed among study group suggested that the education about correct inhaler technique is beneficial. This is supported by Lee et al., (2014) who mentioned that patient's education about correct inhaler technique showed increase the effectiveness of the inhaled medication and relieving symptoms especially dyspnea [46]. 
The results of the current study showed that there was a statistical significance difference between mean dyspnea severity scores in relation to disease duration among study group. This may be related to the severity of the disease increase with increase duration of the disease and so manifestations such as dyspnea increase in severity.

\section{Medication adherence}

Although medical treatment of chronic obstructive pulmonary disease has advanced, non adherence to medication regimen poses a significant barrier to optimal management [37]. Non adherence to medication regimens is common among COPD patients because of chronic nature of the disease and the use of multiple medications especially they are often prescribed areolized medications to use from two to six times daily [47, 48]. Haupt et al., (2008) stated that chronic obstructive pulmonary disease patients display significant low adherence to treatment [49]. Agh et al., (2011) showed that patients adhered to treatment poorly when they had several drugs prescribed [50]. This is in line with the result of the present study which illustrated that pre education, majority of both groups had low adherence to medication regimen.

It was reported that patient's knowledge of the disease process as well as the recommended treatment are critical for optimal medication adherence in patients with COPD [51]. Also several observational studies have shown that training patients on inhaler use improve not only inhalation technique but also adherence to treatment and so disease control [52, 53]. This illustrates the finding of the current study that showed significant improvement in medication adherence among intervention group than control group after education about correct use of inhaler. This result supported hypotheses number two. Also this result is supported by pervious cross sectional study that revealed that instruction about inhalation technique repeatedly provided for chronic obstructive pulmonary disease patients contributes to therapeutic adherence [53].

The results of the current study revealed that mean medication adherence among both study and control groups didn't differ according to age, educational level of participants and their disease duration. This result in line with other studies carried by Wisniewski et al., (2014) and Agh et al., (2011) who reported that patient's age was not a factor that increase their adherence to treatment $[32,50]$. Moreover Wisniewski et al., (2014) didn't find any relation of medication adherence with education [32].

\section{Conclusion}

Based on the results of current study, it was concluded that, education about chronic obstructive pulmonary disease and correct inhaler use was effective in significantly improving total knowledge score among study group than control group. Also Poor inhalation technique is common among subjects of both groups and correct inhaler technique education appears vital to significantly improve performance of inhaler among study group than control group.
Severity of dyspnea reduced among study group than control group after correct inhaler education however the reduction of dyspnea severity was not significant. Moreover education about proper inhalation technique resulted in significant improvement of adherence to inhalation therapy among study group than control group.

\section{Recommendations}

Based on the findings of the current study, the following recommendations can be suggested:

1. Patients with chronic obstructive pulmonary disease must be regularly evaluated for their inhaler technique and reinforced to maintain correct technique because it can be deteriorated again after education.

2. A colored booklet about proper inhalation technique supported by pictures for almost each step should be distributed to all COPD patients.

3. Replication of the study using a large probability sample from a broad geographical area to allow greater generalization of the results.

4. Replications of the study with long period of follow up to allow for greater understanding the effect of inhaler technique on dyspnea severity and allow for greater generalization of the results.

\section{References}

[1] World Health Organization. (2012). Retrieved from http://www.who.int/gho/publications /world_health_statstics/2012. Accessed on 27- 9- 2015

[2] Rennard S. (2014) Patient information: Chronic obstructive pulmonary disease treatments. Lancet; (1): 1-6.

[3] National Institute of Health: (2008). Global strategy for the diagnosis, management and prevention of chronic obstructive pulmonary diseases. Retrieved on December 2015.

[4] Chronic obstructive pulmonary disease (COPD) Fact sheet No 315. 2007:

http://www.who.int/mediacentre/factsheets/fs315/en/index.ht $\mathrm{ml}$.

[5] World Health Organization. (2016). Chronic respiratory diseases. Available at

$\mathrm{http}: / / \mathrm{www}$.who.int/respiratory/copd/burden/en/ retrieved on $31 / 1 / 2016$

[6] Nunes D., Mota R., Neto O., Pereira E., de Bruin V. and de Bruin P. (2009). Impaired sleep reduces quality of life in chronic obstructive pulmonary disease. Lung; 187: 159-63.

[7] National institute of health (2001) Global initiative for chronic obstructive pulmonary disease: Global strategy for the diagnosis, management and prevention of chronic obstructive pulmonary disease. U.S department of health and human services, NIH publication number 2701B.

[8] Nunes D., Mota R., Neto O., Pereira E., de Bruin V. and de Bruin p.(2009) impaired sleep reduces quality of life in chronic obstructive pulmonary disease. Lung; 187: 159-63. 
[9] Janssen D., Franssen F., Wouters E., Schols J. and Spruit M. (2011) Impaired health status and care dependency in patients with advanced COPD or chronic heart failure. Quality of life research; 20: 16, 79-88.

[10] Rocker G., Horton R., Currow D., Goodridge D., Young J. and Booth S. (2009) Palliation of dyspnea in advanced COPD: Revisiting a role for opioids. Thorax; 64: 910-5.

[11] Marciniuk D., Goodridge D., Hernandez P., Rocker G., Balter M., Bailey P., Ford G., Bourbeau J., O'Donnell D., Maltais F., Mularski R., Cave A., Mayers I., Kennedy V., Oliver T., and Brown C., (2011). Managing dyspnea in patients with advanced chronic obstructive pulmonary disease: A Canadian Thoracic Society clinical practice guideline, Can Respir J; 18 (2): 69-78.

[12] Global Initiative for Chronic Obstruction Lung Disease (2011). Global strategy of the diagnosis, management and prevention of chronic obstructive pulmonary disease. The GOLD Workshop Report, 65-86. Available at http:// www.goldcopd.org/guidelines-global-strategy-for-diagnosismanagement.html retrieved on 27-9- 2015

[13] Crompton G., Barnes P. Broeders M., Corrigan C., Corbetta L. and Dekhuijzen, R. (2006). The need to improve inhalation technique in Europe: A report from the Aerosol drug management improvement team. Resp Med.; 100: 1479-94

[14] Cochrane M., Bala M., Downs K., Josephine M and BenJoseph R. (2000). Inhaled corticosteroids for asthma therapy: Patient compliance, devices, and inhalation technique. Chest; $117,542-50$.

[15] Roche N., Chrystyn H. Lavorini F. Agusti A. Virchow C. Dekhuijzen R. and Price D. (2013). Effectiveness of inhaler devices in adult asthma and COPD. EMJ Respir; 1 (1): 64-71.

[16] Hesselink A., Penninx B and Wijnhoven H..(2001). Determinants of an incorrect inhalation technique in patients with asthma or COPD. Scan J Prim Health Care; 19: 255-60

[17] National Asthma Council Australia. (2008). Inhaler technique in adults with asthma or COPD. Available at www. National asthma. org.au. 1-9 retrieved on 19-4-2016

[18] Takemura M., Mitsui K., Ido M., Matsumoto M., Koyama M., Inoue D., Takamatsu K., Itotani R., Ishitoko M., Suzuki S., Aihara K., Sakuramoto M. Kagioka H. and Fukui M.(2013) Effect of a network system for providing proper inhalation technique by community pharmacists on clinical outcomes in COPD patients. International Journal of COPD; 8 (1): 239- 44.

[19] Vestbo J., Anderson J. and Calverley P. (2009) Adherence to inhaled therapy, mortality and hospital admission in COPD. Thorax; 64 (11): 939- 43.

[20] Kaplan R, Ries A. (2005). Quality of life as an outcome measure in pulmonary diseases. J Cardiopulm Rehabil. 25: 321-31.

[21] Rodriguez-Roisin R. (2005). The airway pathophysiology of COPD: implications for treatment. Int $\mathrm{J}$ Chron Obstruct Pulmon Dis. 2005; 2: 253-62.

[22] White R. Walker P., Roberts S., Kalisky S. and White P.(2006) Bristol COPD Knowledge Questionnaire: Testing what we teach patients about COPD. Chronic Respiratory Disease, 3, 123-31. dio: 10.1191/1469972306cd117oa.

[23] Lee H., Boo S., Lim Y., Kim S. and Kim I. (2014) Accuracy of inhaler use in patients with COPD. Clinical Nursing Research; 23 (5): 560-74.

[24] Eakin E., Resinkoff P., Prewitt L., Ries A. and Kaplan $R$.(1998) Shortness of breath questionnaire. Chest; 13 (1): 619-24.

[25] Tabberer M., Brooks J. and Wilcox T.(2015) A meta analysis of four randomized clinical trials to confirm the reliability and responsiveness of the shortness of breath with daily activity questionnaire in chronic obstructive pulmonary disease. Health and quality of life outcomes; 13: 177

[26] Morisky D., Green L. and Levine D. (1986) Concurrent and predictive validity of a self reported measure of medication adherence. Med Care; 24: 67-74.

[27] Moharamazad Y., Saadat H., Shahraki N., Rai A., Saadat Z., Aerab- sheibani H., Naghizadeh M. and Morisky D. (2015) Validation of the Persian version of the 8 item Morisky medication adherence scale in Iranian hypertensive patients. Global Journal of health science; 7 (4): 7

[28] Dawson B., and Trapp R., (2001): Reading the medical literature: Basic \& Clinical Biostatistics. $3^{\text {rd }}$ ed., New York. Lange Medical Book/ McGraw - Hill. Medical Publication Division, 7-9, 161-218, 305-14.

[29] Lavorini F., Magnan A., Dubus J., Voshaar T., Corebetta L., Broedres M., Dekhuizen R., Sanchis J., Viejo J., Barnes P., Corrigan C., Levy M. and Crompton G.(2008). Effect of incorrect use of dry powder inhalers on management of patients with asthma and COPD. Respir Med.; 102 (1): $593-$ 604.

[30] Salah M., Hamdi A. and Shehata H.(2013). Improving breathlessness and fatigue in patients with COPD. Journal of American Science; 9 (12): 470-82.

[31] Tel H., Bilgic Z. and Zorlu Z. (2012). Evaluation of dyspnea and fatigue among the COPD patients, Chronic obstructive pulmonary disease- current concepts and practice. Available at: $\quad$ http://www.intechopen.com/books/chronic obstructivepulmonary-disease-current-concepts and practice/evaluation of -dyspnea-and- fatigue-among the -copd patients.

[32] Wiśniewski D., Porzezińska M., Gruchała-Niedoszytko M., Niedoszytko M., Marek J., Jassem W. (2014). Factors influencing adherence to treatment in COPD patients and its relationship with disease exacerbations. Pneumonol. Alergol.; 82: 96-104.

[33] Akinci A. and Yildirim E. (2013). Factors affecting health status in patients with chronic obstructive pulmonary disease. International journal of Nursing Practice; 19 (1): 31-8.

[34] National Heart, Lung, and Blood Institute (2013). COPD are you at risk? Last updated 2011; accessed 2013 Feb 11.

[35] Fernandez J., Fernandez F., Ruiz A., Torres D. and Fonseca P. (2014). Efficacy of a multifactorial intervention on therapeutic adherence in patients with chronic obstructive pulmonary disease: A randomized controlled trial. BMC Pulmonary Medicine; 14: 70-83

[36] Fadaei S., Pourahmad M., Asghari M., Kohan M. and Sepidkar a. (2014). Correct or incorrect use of inhalers in patients with dyspnea. Pars Journal of Medical science; 12 (2): $23-8$. 
[37] Restrepo R., Alvarez M., Wittnebel L., Sorenson H., Wettstein R., Vines D., Sikkema- Ortiz J., Gardner D. and Wilkins R. (2008). Medication adherence issues in patients treated for COPD. Int J Chron Obstruct Pulmon Dis.; 3 (3): 371-84.

[38] Bieber J. and Terkeltaub R. (2007). Gout: On the brink of novel therapeutic options for an ancient disease. Arthritis Rheum; 50 (3): 2400-14.

[39] Khdour M., Kidncy J., Smyth B. and McElnay J. (2009). Clinical pharmacy-led disease and medicine management programme for patients with COPD. Br J Clin Pharmacol.; 68 (4): 588-98.

[40] Jarab A., Alqudah S., Khdour M., Shamssain M. and Mukattash T. (2012). Impact pharmaceutical care on health outcomes in patients with COPD. Int Clin Pharm.; 34 (1): 5362 .

[41] Elsayed H., Weheida S. Mohsen M. and Shehata A. (2012): The effect of knee range of motion exercise on knee pain and activity of daily living after arthroscopic anterior cruciate ligament reconstruction. Innovation in Nursing researches, education and practice. International conference of Kennesaw state and Helwan universities.

[42] Rootmensen G., Van Keimpema A., Jansen H. and de Haan R. (2010). Predictors of incorrect inhalation technique in patients with asthma or COPD: A study using a validated videotaped scoring method. Journal of Aerosol Medicine and pulmonary drug delivery; 23: 1-6.

[43] Marciniuk D., Goodridge D., Hernandez P., Rocker G., Balter M., Bailey P., Ford G., Bourbeau J. O'Donnell D., Maltais F., Mularski R., Cave A., Mayers I., Kennedy V., Oliver T. and Brown C. (2011). Managing dyspnea in patients with advanced chronic obstructive pulmonary disease: A Canadian thoracic society clinical practice guideline. Can Respir J.; 18 (2): 69- 78 .

[44] Rabe K. (2006). Improving dyspnea in chronic obstructive pulmonary disease optimal treatment stratigies. ATS Journals.; 3 (3) $270-5$
[45] Melani A., Bonavia M., Cilenti V., Cinti C., Lodi M., Martucci $P$. and Neri M. (2011). Inhaler mishandling remains common in real life and is associated with reduced disease control. Respiratory Medicine; 105 (1): 930-38.

[46] Lee H., Boo S., Lim Y., Kim S. and Kim I. (2014). Accuracy of inhaler use in patients with chronic obstructive pulmonary disease. Clinical Nursing Research; 23 (5): 560- 74.

[47] Stuart B. (2004). Navigating the new medicare drug benefit. Am J Geriatr Pharmacother. Pub Med.; 2: 75-80.

[48] Krigsman K., Lars J. and Ring L. (2007). Refill adherence for patients with asthma and COPD: Comparison of a pharmacy record database with manually collected repeat prescriptions. Pharmacopidemiol Drug Saf.; 16 (1): 441-8.

[49] Haupt D., Krigsman K. and Nilsson J. (2008). Medication persistence among patients with asthma/COPD drugs. Pharm World Sci.; 5.

[50] Agh T., Inotai A., Meszaros A. (2011). Factors associated with medication adherence in patients with chronic obstructive pulmonary disease. Respiration; 82: 328-34.

[51] Di Matteo M., Haskard K. and Williams S. (2007). Health beliefs, disease severity and patient adherence: A meta analysis. Med care; 45 (1): 521-8.

[52] Ammari W. and Chrystyn H. (2013). Optimizing the inhalation flow and technique through metered dose inhalers of asthmatic adults and children attending a community pharmacy. J Asthma; 50: 505-13.

[53] Takemura M., Mitsui K., Ido M., Matsumoto M., Koyama M., Inoue D., Takamatsu K., Itotani R., Ishitoko M., Suzuki s., Aihara K., Sakuramoto M., Kagioka H. and Fukui M. (2013). Effect of a network system for providing proper inhalation technique by community pharmacist on clinical outcomes in COPD patients. Int J Chron Obstruct Pulmon Dis.; 8: 239-44. 